\title{
Challenges and Impacts of Human Resource Outsourcing (HRO) in Bangladesh
}

\author{
Maksuda Hossain \\ Assistant Professor, Faculty of Business Administration \\ Eastern University, Dhanmondi, Dhaka \\ E-mail: maksuda@easternuni.edu.bd
}

Abu Md. Abdullah

Assistant Professor, Faculty of Business Administration

Eastern University, Dhanmondi, Dhaka

E-mail: abdullah@easternuni.edu.bd

Received: May 25, 2017 Accepted: June 7, 2017 Online published: July 19, 2017

doi:10.5296/ijhrs.v7i3.11568ＵRL: https://doi.org/10.5296/ijhrs.v7i3.11568

\begin{abstract}
By HRO we mean using a third party to undertake HR functions for an organization. In Bangladesh, from the last ten to twelve years many private organizations (non-govt.) are getting accustomed with the practice. Cost and time reduction, touch of expert work etc. are the various reasons for which the practice is getting significance day by day. But the organizations that are providing services are facing some challenges. The purpose of the study is to work with these challenges in depth. As it is a very new practice the numbers of service providers are very limited (not more than 30 ) in the country.

For data collection a questionnaire including both open-ended and close-ended questions was designed. Situational cases were also used. From the study it is found that govt. rules-regulations, service quality of providers and mismatch with organizational culture firms are the main sources of challenges in this sector.
\end{abstract}

Keywords: Human resource outsourcing, Service providers, Service takers, Human resource functions. 


\section{Introduction}

In business, outsourcing is the contracting out of a business process to a third-party. The term "outsourcing" became popular in the United States near the turn of the 21st century (Nawab, 2013). Outsourcing is also used to describe the practice of handing over control of public services to for-profit corporations (Basu, 2015). Manpower outsourcing or human resource outsourcing is slowly becoming the buzz in Bangladesh and the trend not only hit the multinational companies but also the public sectors and government undertakings as well. Most small-business owners know the frustration of spending more time than they want or should on non-revenue-generating activities. From payroll and human resource management to benefits and compensation, entrepreneurs can spend up to 40 percent of their precious day engaged in these necessary but time-sucking tasks. Businesses that outsource HR are typically small-to-midsize firms with between 25 and 1,500 employees. These businesses view HR outsourcing as a strategic tool that relieves them of HR responsibilities and enables them to focus on what they do best.

The aim of the study is to identify the challenges and impacts of HRO in the light of survey of various outsourcing firms providing HR services in our country.

\section{Review of Literature}

Not all the organizations are totally self-sufficient, nor competent internally; they have depend other firms or third parties to get their works done competitively; like, hiring employees, getting IT solutions or market survey for launching new product. Conceptually, this process of taking services from others is called "outsourcing" and the firm/firms from whom services are received called "outsourcing firm". So, outsourcing is using another source (out + source). This is a contractual relationship between the organization and the service provider (Butler, Callahan \& Smith, 2007, p.3). But in terms of strategy, outsourcing should be considered as a long term activity designed to ensure not only the survival but also the prosperity of the enterprise (Andone \& Pavaloaia. 2010. p.163) . In the 1990s, as organizations began to focus more on cost-saving measures, they started to outsource those functions necessary to run a company which are not related specifically to the core business. Managers contracted with emerging service companies to deliver accounting, human resources, data processing, internal mail distribution, security, plant maintenance, and the like as a matter of "good housekeeping" (Handfield, R. 2006). The decision to outsource may be purely financial, but may also have strategic implications (Norman, p.2).

If we go through the history of outsourcing we found that outsourcing was not formally identified as a business strategy until 1989 (cited in Handerfield, 2006). The term outsourcing is first used in IT sector. Now-a-day, the scope of outsourcing has broadened. Outsourcing of Human Resource functions or Human Resource Outsourcing (HRO) is now becoming a strategic choice for many organizations. As the business is becoming globalized the need of outsourcing is increasing as the outside suppliers produce or serve a good more effectively and efficiently (Yang, et.al. 2007). According to IDS (2000, p.vi), "HR outsourcing involves suppliers taking on a wide range of administrative and/or transactional tasks across the HR function with the aim of providing these more cost effectively through investment in 
technology to automate and standardize process". Different human resource tasks, such as payroll, employee recruitment, benefit administration, employee management are now outsourced by external companies. Occupational health services, pension administration, training and payroll are the most common outsourcing services in UK (Reilly and Tampkin, 1996. p.3); whereas in Bangladesh recruitment and selection are the most common outsourcing services.

HR outsourcing services generally fall into four categories: professional employer organizations-PEOs, business process outsourcings- BPOs, Application service providersASPs or e-services (Sharif and Jamal, 2012, p.1). Business process outsourcing can include transferring an entire business function (e.g. payroll), a production process (e.g. ready-to-install windshield manufacture) or a portion of the related processes (e.g. mailing paychecks, windshield glass delivery) (Norman, p.2). In HR, a BPO would make sure a company's HR system is supported by the latest technologies, such as self-access and HR data warehousing (Aquinas, 2006, p.308). A PEO assumes full responsibility of a company's human resources administration. It becomes a co-employer of that company's workers by taking full legal responsibility of the employees, including having the final say in hiring, firing, and the amount of money employees make. Some HR outsourcing services like to use the recognized term "PEO" when they handle the primary aspects of HR like payroll and benefits, yet they do not take this legal partnership (cited in Sharif, 2012, p.1).

Once there was a myth that only large organizations can use "HR outsourcing"; but it is changing now. Human resources outsourcing can enable smaller companies to grow without making it necessary to hire additional personnel, and by assisting with compliance issues, can help minimize the threat of financial consequences due to a failure to comply with govt.'s employment regulations. So, demand for HRO is also increasing in small organizations.

Some companies outsource one or two activities of HRM, but some large organizations experience outsourcing for their entire HR functions. Whether it is a small, middle or large organization-now-a-day they want to use outsourcing. Most of the companies have no separate HR department and for this they often have no choice except outsourcing of HR activities (Noe, at el, 2006). Not only developed countries, but also developing countries like, India, China are now using HRO. In recent times, a good number of call centers, IT companies and medium sized financial organizations have flourished in Bangladesh. Many of them are using outsourcing services to manage and develop human resources effectively which ensures the right focus on business growth.

In these financially challenged times, small, cash strapped businesses cannot afford any missteps in hiring, firing, or managing their workforce. Furthermore, small businesses bear a greater brunt of employment expenses than their larger counterparts. To ensure company's success, today, many are considering outsourcing critical human resource tasks (Reclaim your business: How Human Resources Outsourcing will enable companies to rebuild in 2012). Cost reduction, time and money savings, specialized services, avoiding lots of paper work are some important motives for HRO (Hesketh, 2006). Another great thing about HRO is that it allows the company to focus on core businesses of the company (Hesketh, 2006, Seth and 
Sethi, 2011, Reilly and Tampkin, 1996).

HRO is becoming a booming business in our country too. Though, in our country, a large number of outsourcing vendors have established and various institutions are taking HR services from those vendors there is a little research have been completed regarding the field. Our neighboring countries like India and Pakistan have also undertaken various researches on this sector whereas we are lagging behind.

\section{Methodology}

It is an explorative study. Both primary and secondary data were collected for the study. Twenty five outsourcing firms were chosen. Population size of the study was 223 executives engaged in service providing \& procurement working in different outsourcing firms from which only 85 were chosen as sample. They were interviewed based on convenient sampling. The primary data was collected through questionnaire survey and the secondary data was collected from various journals, books, newspapers, manuals, articles, annual report, brochure etc. Questionnaire contained both open and close-ended questions with the intension to get in-depth answer. 10 to 12 questions were designed regarding the nature, motives and challenges of HRO. For structured questionnaire 5 point Likert Scale was used because of its easy understanding to the respondents. The scale of responses was: Strongly Agree-5, Agree-4, Neutral-3, Disagree-2 and Strongly Disagree-1. Some open-ended questions were used to allow the respondents to express their views openly. Some questions, especially general information regarding the services were categorized into nominal scale.

Table 2. List of the respondents

\begin{tabular}{|l|l|l|}
\hline Service providers (organizations) & $\begin{array}{l}\text { Population size } \\
\text { (executives } \\
\text { engaged in service } \\
\text { providing } \\
\text { procurement) }\end{array}$ & $\begin{array}{l}\text { Sample size } \\
\text { (executives engaged } \\
\text { in service providing } \\
\& \text { procurement) }\end{array}$ \\
\hline 1. HR Kites & 20 & 8 \\
2. Monowar associates & 14 & 2 \\
3. HR connections & 12 & 3 \\
4. Grow \& excel & 15 & 5 \\
5. ZN consultant & 10 & 3 \\
6. Optima HR solutions & 8 & 3 \\
7. Light House Bangladesh & 10 & 5 \\
8. BDO (business consulting services) & 8 & 4 \\
9. World academy for research \& & 12 & 4 \\
development & 9 & 2 \\
10. A4 consultant & 7 & 3 \\
11. Consumark & 8 & 4 \\
\hline
\end{tabular}




\begin{tabular}{|l|l|l|}
\hline 12. E-ZONE Limited & 9 & 4 \\
13. HR RECO Bangladesh & 8 & 4 \\
14. HR com bd & 8 & 4 \\
15. HR services & 6 & 3 \\
16. HRBD & 7 & 4 \\
17. Infinity HR & 10 & 5 \\
18. Enroute management consulting & 16 & 5 \\
19. People scape & 11 & 4 \\
20. YES private limited & 15 & 5 \\
21. Young consultant & & \\
\hline & 223 & 85 \\
\hline
\end{tabular}

\section{Findings}

\subsection{HR Outsourcing Trends in Bangladesh}

In the last of 2005 many companies, especially the multinational organizations and telecom corporations introduced the practice of outsourcing in HR. That time the $3^{\text {rd }}$ party undertook the major portions of their recruitment which was the starting of HR outsourcing in Bangladesh. Though adequate information are not available about the first HR outsourcing firm, but now-a-day there are more than 20 outsourcing firms who are serving various HR services and many are waiting for their inception. An outsourcing firm can recruit and screen potential employees, navigate government regulations and laws and employment laws and more, all under an employer's (customer) direction. Some HR outsourcing firms are generalists, offering a wide variety of services, while others are specialists, focusing on specific areas such as payroll or recruiting. Depending on the size of the business and how much control an employer wants to maintain over HR functions, one can either outsource all HR tasks or contract for services a la carte (according to the menu). HR outsourcing can be classified into partial or full scales. In partial outsourcing, a client's selected HR functions, such as employee customer service, compensation and benefits, recruitment, learning, payroll, and HR administration, are managed by an outsourced company. In end-to-end or full scale outsourcing, all of a client's HR functions are managed by an outsourced company.

Within the context of HR outsourcing in Bangladesh, the specific processes that are included within any outsourcing arrangement will vary from organization to organization. Some organizations may outsource virtually all of their HR processes, whereas others might select specific components for the purpose. In large organizations, it is a common practice to have outsourced the operational elements of delivering HR services whilst retaining control over strategy and decision-making.

There are a number of well-publicized examples of large, mainly global organizations in Bangladesh, such as Procter and Gamble, Unilever and BT Group (former British Telecom), who outsource most of their HR operational activities, often in contracts of five to 10 years. 


\section{Macrothink}

International Journal of Human Resource Studies

ISSN 2162-3058

2017, Vol. 7, No. 3

Interestingly, small organizations often do the reverse, effectively outsourcing their strategy (to HR consultants and other professional advisers) and keeping the HR delivery processes internal. Organizations can begin by dividing HR services into three categories -- strategic, tactical and administrative --from the highest value to the lowest. Strategic activities include corporate culture, organizational development, and personnel resource planning, compensation and benefit design. Tactical activities include compliance, talent acquisition and retention, performance appraisal, employee relations and training. The administrative activities include day-to-day transactions related to payroll, benefits enrolment and employee record keeping.

The administrative functions are suited to outsourcing, while the tactical and strategic functions are more suited to be managed internally.

Once an organization identifies the function to be outsourced, it floats a RFP (request for proposal) from outsourcing service companies, conducts weigh-ins (cost-benefit analysis) and decides on outsourcing. While generally people think that outsourcing is always done as a cost-cutting measure, they should look at it from the value generation perspective instead.

\subsection{Services That Are Outsourced}

HR outsourcing in Bangladesh is still in its infancy. Functions like payroll and benefits administration (leave and medical benefit administration and provident funds) are outsourced, and training and development are outsourced to an extent as well. But the most pressing outsourcing activities in our country is headhunting or recruitment and selection. Figure.1 shows the sector wise pattern of outsourcing services providing by our outsourcing firm.

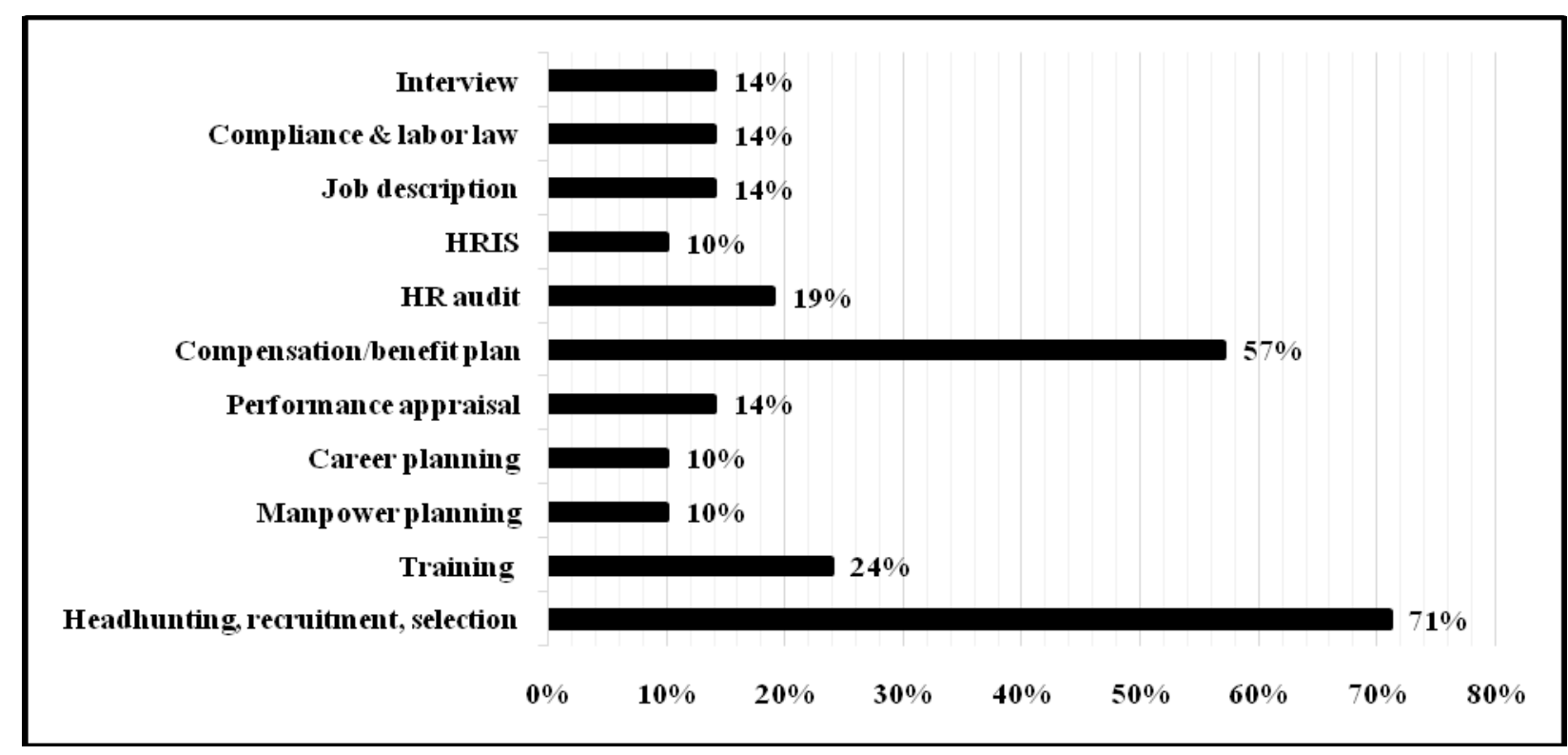

Figure 1. Sector wise service providing by HR outsourcing firms in BD according to their website

Source: Interview with service providers 


\section{(a) Headhunting/recruitment/selection}

Mostly international company branches and some multinational companies (for example, Nokia Siemens Networks, IBM, Novartis and Coca Cola) use outsourcing for recruitment and selection. Generally top level and lower level managers, IT executives, marketing executives, care line representatives are recruited through outsourcing firms. To reach the candidates the vendors have large pool of CV banks. Very frequently they use their networks to get the candidates. Poaching is also used by the vendors to reach the talented candidates, especially high-tech employees from the competitors. Both full and part time employees are hired by headhunting firms. Though most of the vendor firms only make a liaison between the job seekers and the job providers some firms undertake advertisements, shortlist of candidates, background check, written and oral exam, medical tests and at last provide placement letters on behalf of the client organization. Based on different factors a search can last from six to ten weeks. Technical criteria, candidate's personality and charisma, communication skill and experiences are the main criteria to choose a candidate. The firms guarantee the replacement, without any extra cost for the candidates who do not meet the expectations of the clients depending upon the position. The cost of a search when recruiting executives in Bangladesh depends on the degree of difficulty of the respective recruitment. There is always a fix fee, independent from the planned salary for the position. The fixed fee is charged on $10 \%$ to $15 \%$ of the gross salary of the candidates based on their number supplied and position. Some outsourcing firms charge first month salary of each employees provided by them as a compensation of their service.

\section{(b) Compensation/benefit plan}

Payroll is another important services provided by outsourcing firms in Bangladesh. Payroll is the sum of all financial records of salaries for an employee, wages, bonuses and deductions. This includes salary payments, tax withholdings, and deductions from a paycheck, wages and responsibility for payment of wages, provident fund and gratuity, workers participation in company's profit and other welfare facilities and benefits etc.

Outsourcing payroll operations to professional services providers can also ensure that foreign businesses are compliant with Bangladesh's compensation and taxation laws. Outsourcing payroll services also include preparation of monthly employee payroll, deposit slips, payroll ledger, and expatriates payroll in Bangladesh (with tax gross up calculation). As per requirement they also make competitors' survey before developing compensation plan for their clients.

For medium size companies or organization, in-house payroll management is effective and manageable but for small size companies it will increase the admiration and management cost considerably. While for other big organizations working with large group of employees need extra staff members to manage the entire payroll management with high cost on entire payroll management. Outsourcing payroll management can be very useful and cost-effective for both small and large companies.

(c) Training 


\section{Macrothink}

International Journal of Human Resource Studies

ISSN 2162-3058

2017, Vol. 7, No. 3

A large number of training institutes are available for the professionals and fresher throughout the country. They are offering IT based training, managerial training and so on. People individually, or sometimes organizations recommend employees for such training courses. WARD, BD jobs training, NIIT are the worth mentioning training institute in Bangladesh. Demand is also increasing in labor law and compliance training which keeps employer and employee update and clarify the comparative understanding of changes of Bangladesh labor laws for executive and managers responsible for managing human resources, industrial relations and employee relations for ensuring appropriate applications in the workplaces. Such training does not only provide practical insights regarding all aspects of Bangladesh labor laws but also put special emphasis on Bangladesh labor (amendment) law 2016.

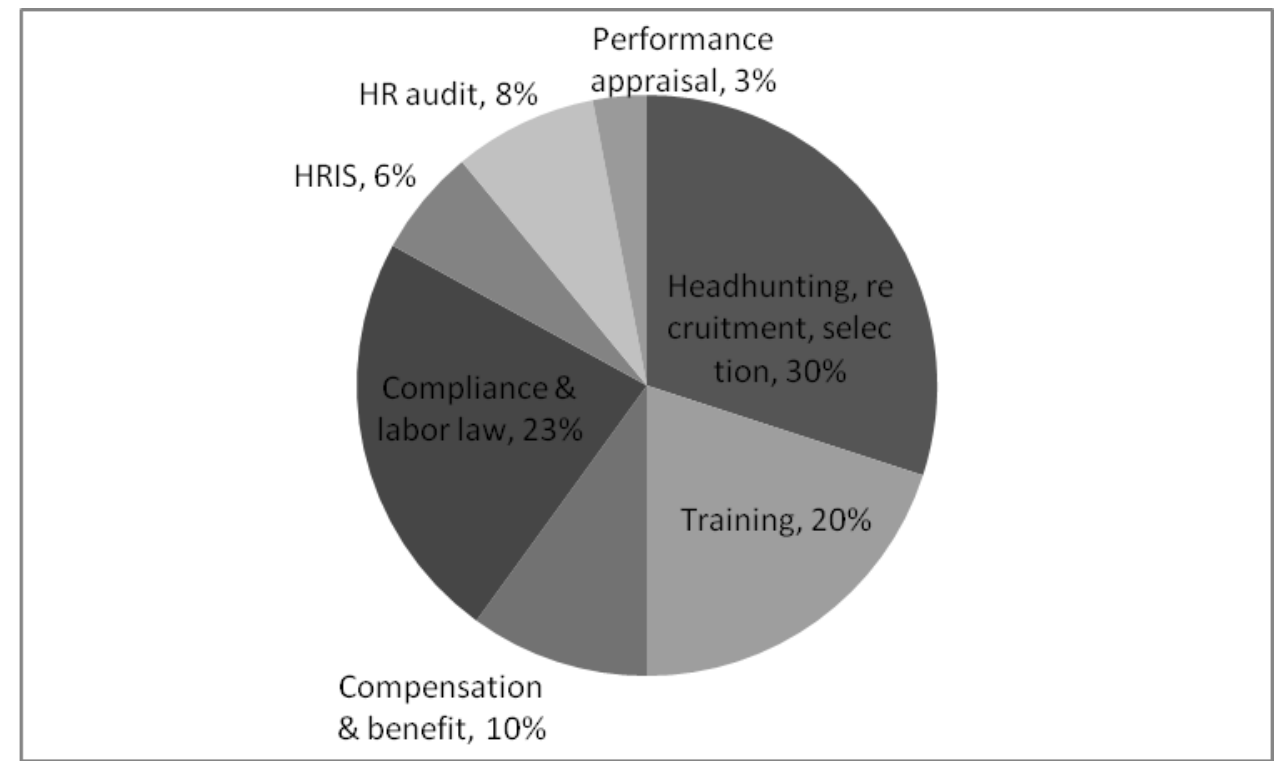

Figure 2. Demand for HRO services in BD according to sample survey

\section{(d) Labor law and compliance}

Tragedies one after another galvanized the world's attention around the issue of worker safety especially in garment sector in the country. Understanding and upholding labor law and compliance are now giving importance by many of the owners of the garments and other manufacturing organizations. Besides providing training on this the outsourcing firms are providing other services like understanding different modes of employment separations, understanding misconducts and its classifications, disciplinary actions \& domestic inquiries, handling of grievances, classification of workers and their differences, conditions of service \& employment, working hours/ overtime entitlements and calculations, annual leave/ other leaves and holidays, maternity benefits and payments, fire \& safety provisions and accident preventive measures etc.

\subsection{Importance of $H R O$ in $B D$}

Though there are large number reasons for using HRO, like: cost and time minimization, reducing risk, efficiency, employee development etc.; but in Bangladesh most of the organizations are using outsourcing because of two reasons. The most obvious benefit of 
outsourcing human resource functions is saving the organization money through cutting costs. Setting up an in-house HR department needs plenty of back-office expenses, which do not generate any new revenue throughout the year. In addition, a fully functioning $\mathrm{HR}$ department needs highly trained staff and extra office space, all of which can cost huge sums of money. HRO reduces costs by the following ways: (a) it saves operating costs, (b) it improves compliance which reduces legal risk, (c) HRO reorganizes HR functions, (d) HRO helps to focus on one's core business which ultimately reduce wastage, (e) it also reduces number of HR staff and the cost of maintaining them, and the last is (f) it also reduces the cost of technology investment. The second benefit from HRO in Bangladesh is it provides more expert work than an in-house HR department. It happens by the following ways: (a) HRO gives opportunity to use the expertise of vendors, (b) it provides consistent and improved services, and (c) it gives access to vendor's technology. Sector wise information regarding the importance of $\mathrm{HRO}$ in $\mathrm{BD}$ is given below (table.2):

Table 1. Sector wise importance of HRO in BD

\begin{tabular}{|c|c|}
\hline Sectors & Importance \\
\hline Recruitment/selection/headhunting & $\begin{array}{l}\text { - Low cost } \\
\text { - } \quad \text { Less uncertainty regarding employee quality. } \\
\text { - } \quad \text { Facility to replacement in case of turnover. } \\
\end{array}$ \\
\hline Training & $\begin{array}{l}\text { - Recent and demanding training topics are easily } \\
\text { recognized. } \\
\text { - Easy access to skilled trainer } \\
\text { - Easy access to large number of candidate pool. } \\
\text { - Unavailability of Venue/training centre can easily } \\
\text { be removed. }\end{array}$ \\
\hline Compensation \& benefit plan & $\begin{array}{l}\text { - Competitors' strategy can easily be identified } \\
\text { - New policy can be included with higher } \\
\text { expertise. }\end{array}$ \\
\hline Compliance \& labor law & $\begin{array}{l}\text { - Keep update on recent labor law and compliance } \\
\text { policy of the country. }\end{array}$ \\
\hline HR audit & $\begin{array}{l}\text { To identify the gaps, lapses, irregularities, } \\
\text { short-comings, in the implementation of the } \\
\text { Policies, procedures, practices of the Human } \\
\text { Resource Department and to suggest remedial } \\
\text { actions. } \\
\text { To know the factors which are harmful to the } \\
\text { non-implementation or wrong implementation of } \\
\text { the planned programs and activities. }\end{array}$ \\
\hline HRIS & $\begin{array}{l}\text { - Use and easy access to update technology } \\
\text { - } \quad \text { Low cost }\end{array}$ \\
\hline Performance appraisal & $\begin{array}{l}\text { - Helps to maintain transparency in performance } \\
\text { management }\end{array}$ \\
\hline
\end{tabular}




\section{Macrothink}

\subsection{Challenges of HRO in Bangladesh}

The concept of HRO is new. Proper understanding has not developed yet in the mind of both service takers and providers. Beside this, many constraints come from the laws and legislation of the country. And for these reasons the path of outsourcing of various HR functions are not very easy that was expected before. Challenges of HRO in Bangladesh are divided into 2 categories: 1. Obstacles related to laws and legislations and the other is 2 . Obstacles related to vendors and clients. Clients' perceptions regarding the challenges are highlighted in table 3.

\section{Obstacles from laws \& legislations}

(a) Corporate tax is increasing: in Bangladesh, corporate tax for an $\mathrm{HRO}$ firm is increasing day by day. Study suggested that in 2008 such firms had to pay $4.5 \%$ tax to the govt. on their income. But in 2016 the corporate tax rate has come to $10 \%$ which is increasing service charges receiving from the clients.

Table 2. Tax rate of outsourcing firms from 2005 to 2016

\begin{tabular}{|c|c|c|c|}
\hline Year & Tax rate $(\%)$ & Year & Tax rate $(\%)$ \\
\hline 2005 & - & 2011 & 8 \\
\hline 2006 & - & 2012 & 8 \\
\hline 2007 & - & 2013 & 9 \\
\hline 2008 & 4.5 & 2014 & 10 \\
\hline 2009 & 5 & 2015 & 10 \\
\hline 2010 & 6 & 2016 & 10 \\
\hline
\end{tabular}

Source: National Board of Revenue

(b) Quality of contract is poor: a contract made between vendor and a customer always not good in quality. Sometimes rules and regulation and conditions are not written down properly in the contract. In developing an outsourcing contract the following issues must be present: introduction of the both parties with clear understanding, detailed explanation of the service required from the both parties, rights of the parties, steps taken in an unexcused failure and end signature of both parties. In absence of these features the outsourcing contract will become unhealthy.

- Case 01: in 2005 Mr. A and Mr. B (both name were kept hidden) signed an outsourcing contact between themselves. Mr. A was the representative of the vendor and Mr. B was of customer. After few days of signing contact it was revealed that Mr. A was not a member of vendor and made financial loss of the customer.

- Case 02: In 2008, a contract was developed between an IT consultant Y and an outsourcing firm $\mathrm{Z}$ (the name kept hidden) in Dhaka city. Y ordered for 50 care-line officers from $\mathrm{Z}$ where the qualities of the candidates were not written down properly. When $\mathrm{Y}$ 
received the candidates their expectation did not match. After waiting 2 months $\mathrm{Z}$ replaced the employees as per their expectations.

(c) Existence of hidden cost: there are a large number of hidden costs in the contact which cannot be possible to mention while making a contact. Such hidden costs may include, bargaining costs, monitoring costs, costs from currency fluctuation, costs from technology maintenance, cost of outdated outsourcing strategy, cost of unforeseen risks, cost of poor or substandard quality etc. For example, several executives even instructed that "X levels of outsourcing be achieved by $\mathrm{Y}$ date" without any analysis at all. Along the way, companies became confused about the difference between price and total landed cost, and they failed to consider all of the cost factors associated with outsourcing. These hidden costs typically add up to somewhere between 14 percent and 60 percent of purchase price. Study suggested that many organizations are still far from outsourcing decision because of hidden costs.

Table 3. Perceptions regarding the challenges experienced in BD through HRO

\begin{tabular}{|l|l|l|l|l|l|}
\hline \multirow{2}{*}{ Obstacles } & \multicolumn{2}{l}{ Level of challenges as measures } \\
\cline { 2 - 6 } & $\begin{array}{l}\text { Strongly } \\
\text { agree }\end{array}$ & Agree & Neutral & Disagree & $\begin{array}{l}\text { Strongly } \\
\text { disagree }\end{array}$ \\
\hline \multicolumn{2}{|c|}{$\begin{array}{l}\text { Obstacles from laws \& legislations } \\
\text { charge is increasing }\end{array}$} & $45 \%$ & & & \\
\hline Quality of contact is poor & & $83 \%$ & & & \\
\hline Existence of hidden cost & & & & $67 \%$ & \\
\hline & & $66 \%$ & & & \\
\hline Poor working quality & & $33 \%$ & & \\
\hline Lack of qualified service providers & & & $67 \%$ & & \\
\hline Relationship with customers & & & & $83 \%$ \\
\hline $\begin{array}{l}\text { The firms do not provide customized } \\
\text { services }\end{array}$ & & & & \\
\hline Mismatch with company culture & & & & \\
\hline
\end{tabular}

2. Obstacles from vendors and clients

(a) Poor working quality: the top risk of a service provider is its poor working quality. Like other business organizations, outsourcing company is also motivated by profit. Since the contract will fix the price, the only way for them to increase profit will be to decrease expenses. To decrease expenses sometimes both parties compromise their quality. When the quality of services provided by vendors is deemed unsatisfactory, the cost of an alternative solution increases, and any immediate improvements may be difficult to materialize. It is very hard to found an ISO 9000 certified outsourcing firm. 
Sometimes the vendors cannot maintain quality while auditing clients' HR quality because of pressure from management and biasness. In our country very frequently management of clients' organization wants such a report from the auditors that shows no discrepancies. As a result they have to make "always good" report.

(b) Lack of service providers: as the business is still in inception stage, there is a lack of quality service providers in the industry. Some of them also lack of expertise. In our country, at present there are only 8-10 service providers who can provide quality services. They have created monopoly in the market. Service providers agreed that there is no authorized list of HR outsourcing firms in Bangladesh.

(c) Relationship with customers: clients have the whole right to reject employees if they cannot fulfill clients' need. But if clients dismiss employees without informing the vendors it may hamper relationship between clients and vendors.

(d) Customized services: As the vendor has to work with many firms at a time, some vendors have the tendency to provide standard products instead of customized one, they deny to add customized features as per customers need. The example is applicable in setting HR software in case of HRIS outsourcing. In other words, sometimes customers search for special features without paying more.

(e) Mismatch with company culture: though it is not very much obvious in case of outsourcing within same country, but sometimes employees provided by the vendor do not match with the client company. According to the vendors about 5\% clients scare the mismatch with company culture.

\subsection{Impacts of $H R O$ in $B D$}

As the practice started recently and headhunting is the significant component of HRO in our country both positive and negative impacts are present in this part. HRO firms have lessened the importance of HR department in many small and middle sized firms. Some of them partially undertake outsourcing of HR tasks. The telecom companies, though have strong HR department they use HRO firms for recruiting care-line officers, mostly. They are also trying to give the full responsibility of headhunting to the vendors. Dependency on contractual jobs is increasing day by day with the beginning outsourcing firms. Another impact which lies in training and development outsourcing is, many organizations do not maintain training center for their employees; rather they go for outsourcing a risk and burden free training services.

Negative impacts are also available here. Some of the examples are:

First, many client organizations in Bangladesh pay lower salary to the outsourced employees than the in-house employees. As there is a provision that the outsourced employees will receive compensation from the outsourced firms; sometimes, the organization where they work doesn't pay any incentives or bonuses properly. In a telecom company from Bangladesh the part time care line representatives hired in 2009-10 or before were provided tk. 5,000 as monthly cellphone bill as incentives. Employees were also facilitated by organizational transport. But in 2016 the cellphone bills have been reduced to tk. 3000 and transport facility 
is also deducted as the organization has started to use outsourcing firms for recruitment.

Second, alike poor salary structure identity crisis is another negative consequence of outsourcing of recruitment process. Outsourced employees cannot consider themselves as the employees of client organization though they work in the premises of the organization. They are always treated as the employees of the third party.

Third, in our country a large pool of candidates are outsourced as care line representatives in different call centers and telecom companies. They join there as contractual employees with the duration of 3 to 6 months; most of the cases such contact never ends, just extends. Securities of such jobs are very low. Moreover, if the organizations face any financial crisis contractual employees suffer most. Employee layoffs has become a common issue in our country because of the availability of outsourced employees at a lower cost.

\section{Recommendation}

HR outsourcing, one of the new areas of services in Bangladesh, is playing a critical role in business success, offering companies a competitive advantage by giving them access to first-rate talent, tools and expertise. As the service has not yet entered in the maturity level, with the advantages many disadvantages and challenges are also perceived. Most of the challenges are generated through poor policy making. Even in some cases there is no specific policy of the services. Service charges are not fixed as well. Quality service providers are also unavailable and good service providers are taking advantages of it. On the other hand, many young people are exploited by the outsourcing firms. The firms give them opportunity to work without proper evaluation; but when the people cannot meet the performance expectation of the client company they are laid off. Such types of events also lower the morale of peers or other employees recruited through the third party. Govt. should have policy in this regard. However, quality of service and quantity of good firms can be increased through proper monitoring. There must be a standard contact for all the service providers and takers. To get familiar with the hidden costs the service takers should focus on inflation and unemployment rate of the economy. To avoid the mismatch with receivers' culture a rigorous training is needed both from clients and vendors. When selling products and services, companies typically target the largest opportunities first and the smallest customers last. The logic behind this is trying to generate the highest return on the investment. To give customized services the suppliers must have a platinum rule which helps them to provide services as per customers' choice and pattern. Managing outsourced people can give a good result in a flatter organization than a taller. Because employees who get the responsibility to manage the outsourced people have to handle uncertainty more. Without flattering the organization, it will work just an extension of management which is very troublesome. Although outsourcing offers many advantages, it does come with a certain amount of risk. It is found that many firms take people from third party without proper planning, after few months downsize them, again after few months undertake new recruitments. To avoid such a costly hazard the firm should analysis its resources, infrastructure, expertise, technology, security and track record.

By considering these issues a client organization can lessen the challenges received from the 
outsourcing firm.

\section{References}

And one, I. I., \& Pavaloaia, V, W. (2010). Outsourcing the HR services. A1. I. Cuza University of Iasi, Faculty of economics and business administration. Vol. 14(1).

Barrett, R. (2010). Companies find outsourcing can backfire as quality, customer service suffer. Journal Sentinel. Available at: http://www.jsonline.com/business/107011443.html.

Basu, R. (2015). Managing Projects in Research and Development. Gower publishing, 215

Butler, G. M., Callahan, M. C., \& Smith, R. (2007). Human resource outsourcing: performance of service providers. AAA 2008 MAS Meeting Paper. Retrieved from https://papers.ssrn.com/sol3/papers.cfm?abstract_id=1003945

Handfield, R. (2006). A Brief History of Outsourcing. Retrieved from http://scm.ncsu.edu/scm-articles/article/a-brief-history-of-outsourcing on 5.8.2014.

Norman, T. J. (2009). Outsourcing Human Resource Activities: Measuring Hidden Costs and Benefits. Dissertation of Doctor of Philosophy; Faculty of the Graduate School, University of Minnesota, 2.

Yang, D. H., Seongcheol Kim, Changi Nam, \& Ja-Won Min. (2007). Developing a decision model for business process outsourcing. Computers and Operations Research, 34, 3769-3778.

IDS. (2000). Outsourcing HR Administration.

Reilly, P., \& Tamkin, P. (1996). Outsourcing: A Flexible Option For The Future?, IES Report $320,3$.

Aquinas, P. G. (2006). Human Resource Management. Principles and Prcatice ( $1^{\text {st }}$ Ed.) p.308. New Delhi. Vikas Publishing House PVT LTD.

Sharif, T. R. M., \& Jamal, J. (2012). Outsourcing for the management level undertakings: an empirical tudy of the corporate domain of Bangladesh. ISSN: 2251-1571. The international journal's research journal of social science and management, 1(12), 55.

Noe, A. R., Hollenbeck, J. R., Gerhart, B., \& Wright, P. M. (2006). Human Resource Management: Gaining a Competitive Advantage, Mc-Graw Hill, Boston, MA.

Reclaim your business: How Human Resources Outsourcing will enable companies to rebuild in 2012. .CPRhr. http://www.slideshare.net.

Norman, T. J. (2009). Outsourcing human resource activities: measuring the hidden costs and benefits. A dissertation submitted to the faculty of the graduate school of the University of Minnesota. In partial fulfilment of the requirements for the degree of doctor of philosophy.

Hesketh, A. (2006). Outsourcing the HR Function: Possibilities and Pitfalls. Center for performance-Led HR. Lancaster University Management School, p.1 


\section{Macrothink}

International Journal of Human Resource Studies

ISSN 2162-3058 2017, Vol. 7, No. 3

Reilly, P., \& Tamkin, P. (1996). Outsourcing: A Flexible Option for the Future? IES Report, p. 3.

Seth, M., \& Sethi, D. (2011). Human Resource Outsourcing: Analysis Based on Literature Review. International Journal of Innovation, Management and Technology, 2(2), 127

\section{Copyright Disclaimer}

Copyright for this article is retained by the author(s), with first publication rights granted to the journal.

This is an open-access article distributed under the terms and conditions of the Creative Commons Attribution license (http://creativecommons.org/licenses/by/4.0/). 